\title{
Doppler Evaluation of Left Ventricular Diastolic Filling in Children with Systemic Hypertension
}

\author{
A. REBECCA SNIDER, MD, SAMUEL S. GIDDING, MD, ALBERT P. ROCCHINI, MD, \\ AMNON ROSENTHAL, MD, MACDONALD DICK II, MD, DENNIS C. CROWLEY, MD, \\ and JANE PETERS
}

To assess left ventricular (LV) diastolic function in children with systemic hypertension, 11 patients with hypertension (mean blood pressure $99 \mathrm{~mm} \mathrm{Hg}$ ) and 7 normal patients (mean blood pressure $78 \mathrm{~mm}$ $\mathrm{Hg}$ ) underwent $\mathrm{M}$-mode echocardiography and pulsed Doppler examination of the LV inflow. From a digitized trace of the LV endocardium and a simultaneous phonocardiogram, echocardiographic diastolic time intervals, peak rate of increase in LV dimension ( $d D / d t)$, and $d D / d t$ normalized for $L V$ end-diastolic dimension (dD/dt/D) were measured. Doppler diastolic time intervals, peak velocities at rapid filling ( $E$ velocity) and atrial contraction ( $A$ velocity), and the ratio of $E$ and $A$ velocities were measured. The following areas under the Doppler curve and their percent of the total area were determined: first $33 \%$ of diastole ( 0.33 area), first $50 \%$ of diastole, triangle under the $A$ velocity (A area), and the triangle under the $E$ velocity ( $E$ area). The A velocity (patients with hypertension $=0.68$ $\pm 0.11 \mathrm{~m} / \mathrm{s}$, normal subjects $=0.49 \pm 0.08 \mathrm{~m} / \mathrm{s}$ ), the $\mathbf{0 . 3 3}$ area/total area (patients with hypertension $=0.49 \pm 0.09$, normal subjects $=0.58 \pm 0.08$ ), the $A$ area (patients with hypertension $=0.17 \pm 0.05$, normal subjects $=0.12 \pm 0.03$ ), and the $A$ area/total area (patients with hypertension $=0.30 \pm 0.11$, normal subjects $=0.20 \pm 0.07$ ) were significantly different between groups $(p<0.05)$. M-mode and Doppler time intervals, (dD/dt)/D, E velocity, and the remaining Doppler areas were not significantly different between groups. The normal subjects and patients with hypertension did not differ significantly in echocardiographic LV size and thickness or in percent shortening fraction. This study shows that abnormal patterns of LV diastolic filling occur in children with mild systemic hypertension. These diastolic abnormalities are detectable by mitral valve Doppler ultrasound examination when standard M-mode echocardiographic indexes of diastolic function are still normal and before the development of systolic function abnormalities or LV hypertrophy on the M-mode echocardiogram.

(Am J Cardiol 1985;56:921-926)
Several recent echocardiographic and radionuclide studies have demonstrated left ventricular (LV) diastolic filling abnormalities in patients with a variety of cardiac diseases, including coronary artery disease, hypertrophic cardiomyopathy and systemic hypertension. ${ }^{1-13}$ With the use of noninvasive indexes of $\mathrm{LV}$ relaxation and filling, these studies have shown that diastolic dysfunction often precedes systolic dysfunction and is often detectable in asymptomatic patients. $2,4,14$ Some investigators have suggested that diastolic abnormalities are a characteristic finding in adult patients with early hypertensive heart disease. $4,6,10,12$

In this study we assessed LV diastolic function in a group of children with mild systemic hypertension using the noninvasive techniques of $\mathrm{M}$-mode and Doppler cchocardiography, identified the most sensitive Doppler

From the Department of Pediatrics, C. S. Mott Children's Hospital, University of Michigan Medical Center. Manuscript received March 15, 1985; revised manuscript received May 22, 1985, accepted May 28, 1985.

Address for reprints: A. Rebecca Snider, MD, Associate Professor of Pediatrics (Cardiology), F1609, C. S. Mott Children's Hospital, Ann Arbor, Michigan 48109-0010. indexes of $\mathrm{LV}$ relaxation, and compared the M-mode and Doppler techniques in their ability to detect early abnormalities of diastolic compliance.

\section{Methods}

Patients: The patient group included 11 children with systemic hypertension and 7 normal children. The normal group consisted of 3 girls and 4 boys who had no evidence of heart disease on physical examination or on M-mode and 2dimensional echocardiography. They were 10 to 18 years old (mean 15) and weighed 41 to $73 \mathrm{~kg}$ (mean 64). The systolic blood pressure of the normal group at the time of the echocardiographic studies was $111 \pm 8 \mathrm{~mm} \mathrm{Hg}$ (mean \pm standard deviation); the diastolic blood pressure was $62 \pm 8 \mathrm{~mm} \mathrm{Hg}$.

The systemic hypertension group consisted of 6 girls and 5 boys who were randomly selected from the outpatient hypertension clinic. They were 1.4 to 17 years (mean 11) and weighed 8.9 to $75 \mathrm{~kg}$ (mean 42 ). The systolic blood pressure of the hypertension group at the time of the echocardiographic studies was $131 \pm 13 \mathrm{~mm} \mathrm{Hg}$; the diastolic blood pressure was $82 \pm 14 \mathrm{~mm} \mathrm{Hg}$. In the hypertension group, 7 children had essential hypertension, and 1 each had William's syndrome, primary aldosteronism, previous repair of coarctation of the aorta and atrophic pyelonephritis. The time interval from the 


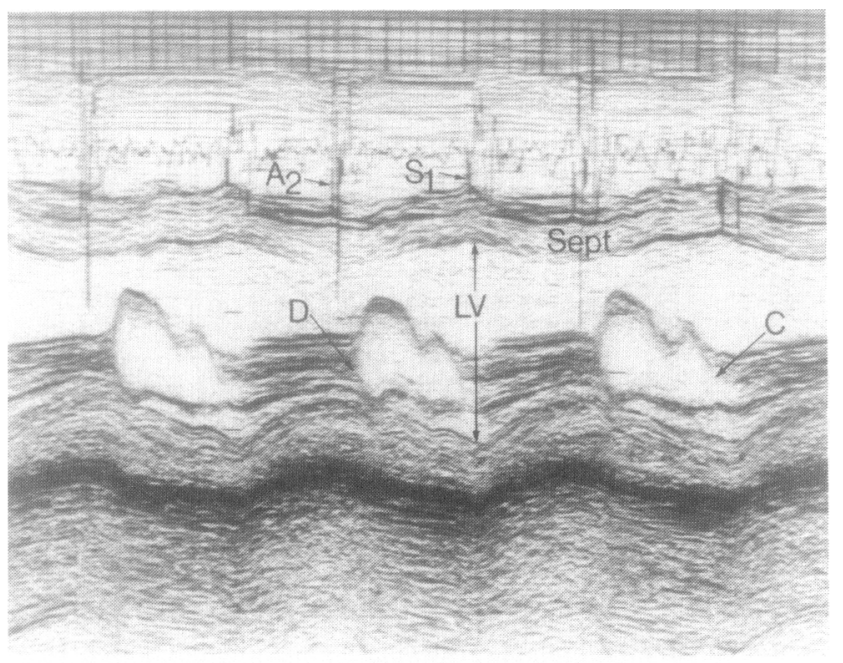

FIGURE 1. M-mode echocardiogram of the left ventricle (LV) with simultaneous phonocardiogram and electrocardiogram. Aortic valve closure $\left(A_{2}\right)$ is the first high-frequency component of the second heart sound. $C=$ mitral valve closure point; $D=$ mitral valve leaflet separation point; $S_{1}=$ first heart sound; Sept $=$ septum.

first recorded elevation of the blood pressure to the echocardiographic study ranged from 1 day to 12 years; mean duration of known hypertension was 2.4 years. At the time of the echocardiographic study, 5 patients with hypertension were receiving no medications, 5 were taking diuretic drugs, 3 were receiving $\beta$-blocking drugs, 1 was taking captopril and 1 was taking hydralazine.

Echocardiographic examination: Each patient underwent an M-mode echocardiographic examination with a simultaneous phonocardiogram and a pulsed Doppler examination of the LV inflow. M-mode echocardiograms of the left ventricle were generated from the 2-dimensional sector scanner (Advanced Technology Laboratories Mark 600, $3-\mathrm{MHz}$ transducer) using a cursor line positioned at the free edges of the mitral valve leaflets in the parasternal short-axis view (Fig. 1). An unfiltered phonocardiogram was obtained from the second left intercostal space and was recorded simultaneously with the M-mode echocardiogram and an electrocardiogram at a paper speed of $50 \mathrm{~mm} / \mathrm{s}$. A record was considered adequate for analysis only when the septal and posterior wall echoes and the time point $D$ of mitral leaflet separation could be clearly identified for at least 3 entire cardiac cycles. Using a hand-controlled pen and a microprocessor system (Digisonics), the echocardiograms were digitized by tracing the endocardial echoes of the septum and the posterior wall. ${ }^{15-17}$ From the digitized tracings, a computer printout of the absolute values of the $\mathrm{LV}$ minor axis dimension and the rate of change of this dimension with respect to time was available at 3 -ms intervals.

From the M-mode echocardiograms, the septum, LV posterior wall and $L V$ dimension were measured at end-diastole at the onset of the QRS wave. ${ }^{18} \mathrm{~L} \mathrm{~V}$ dimension at end-systole was measured as the smallest systolic dimension from the digitized recording. The shortening fraction, the peak rate of increase in dimension ( $\mathrm{dD} / \mathrm{dt}$ ), and the peak rate of increase in dimension normalized for $\mathrm{LV}$ end-diastolic dimension (dD/dt/D) were recorded. The normalization of the lengthening velocity, achieved by dividing the peak $\mathrm{dD} / \mathrm{dt}$ by the $\mathrm{LV}$ end-diastolic dimension, allowed comparison of lengthening velocities between different-sized ventricles. ${ }^{17}$ The following time intervals were measured from either the original M-mode echocardiogram or the digitized tracings ${ }^{3,17}$ :

1. The cardiac cycle length was measured as the time interval between the peaks of 2 successive $R$ waves on the electrocardiogram.

2. The isovolumic relaxation time was measured from the first high-frequency deflection of the aortic closure sound to the initial separation or $\mathrm{D}$ point of the mitral valve leaflets.

3. Protodiastole was measured from the point when $-\mathrm{dD} / \mathrm{dt}$ reaches 0 (the minimum $\mathrm{LV}$ systolic dimension) to the aortic closure sound.

4. The total relaxation time was measured from the minimal LV systolic dimension to the point when $\mathrm{dD} / \mathrm{dt}$ decreases to $50 \%$ of its peak value. This latter point corresponds roughly to the transition between the rapid filling and slow filling phases of diastole. ${ }^{3,17}$

5. The relaxation time was defined as the time from the minimal LV systolic dimension to peak $\mathrm{dD} / \mathrm{dt}$.

6. The rapid filling period was calculated as total relaxation time minus (isovolumic relaxation time + protodiastole).

Doppler examination: Immediately after $M$-mode examination, each patient underwent a range-gated pulsed Doppler examination of the LV inflow tract. Using the apical 4-chamber view, the Doppler cursor line and sample volume were placed in the mitral valve funnel at an angle as nearly parallel to flow as possible (Fig. 2). The sample volume position was adjusted so as to record the maximal velocity through the mitral valve. This point was usually found at the level of

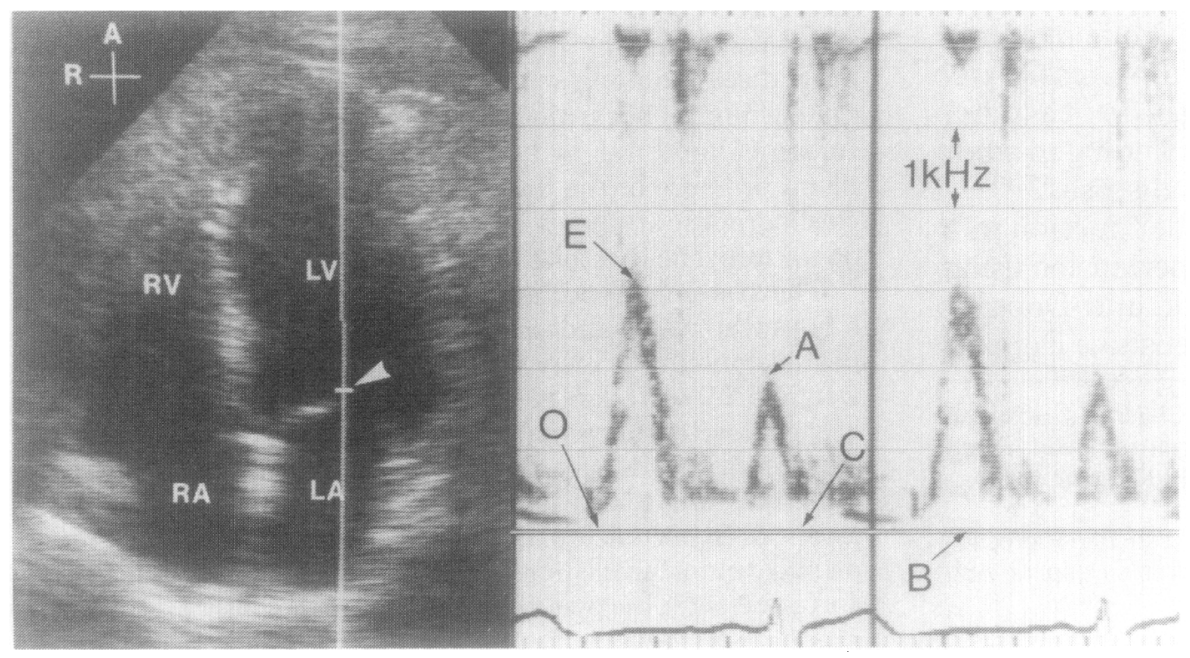

FIGURE 2. Pulsed Doppler spectral recording from the left ventricular inflow. The freezeframe image of the apical 4-chamber view (left) shows the position of the sample volume (white arrow) on the Doppler cursor line at the time of the recording. The mitral valve Doppler spectral tracing (right) shows forward flow toward the transducer and above the baseline (B) during rapid ventricular filling $(E)$ and atrial contraction (A). $\mathrm{C}=$ time point of mitral valve closure; $L A=$ left atrium; $L V=$ left ventricle; $0=$ time point of mitral valve opening; $R A=$ right atrium; $\mathrm{RV}=$ right ventricle. Orientation: $A=$ anterior, $\mathrm{R}=$ right. 
the mitral anulus. ${ }^{19,20}$ All Doppler examinations were recorded with a $3.0-\mathrm{MHz}$ transducer and a paper speed of $50 \mathrm{~mm} / \mathrm{s}$. The Doppler waveform was displayed with frequency shift on the vertical axis, time on the horizontal axis, and amplitude of the signal as shades of gray. Signals from blood flowing toward the transducer were displayed above the baseline and signals from blood flowing away from the transducer were displayed below the baseline. A Doppler examination was considered adequate for analysis only when the opening and closure points ( 0 and $\mathrm{C}$ points) of the mitral valve and the peak velocities at rapid ventricular filling ( $\mathrm{E}$ point) and during atrial contraction ( $\mathrm{A}$ point) could be identified for at least 3 cardiac cycles. The following Doppler time intervals were measured: the $\mathrm{R}$ to $\mathrm{R}$ interval, the time between the 0 to $C$ points, 0 to $E$ points, 0 to A points, the time between the 0 point and the point where the velocity decreases to $50 \%$ of its peak $E$ value (which would be expected to correspond to the rapid filling period), the pressure half-time, ${ }^{21}$ and the time between the 0 point and the point where the velocity decreases to the value of peak E/1.4. This latter point (where the velocity dccreased to peak E/1.4) represents the time at which the $\mathrm{LV}$ diastolic pressure decreases to one-half of its peak value during rapid ventricular filling. ${ }^{2 I}$ The interval between the 0 point and peak $\mathrm{E} / 1.4$ was included as another technique for measuring the rapid filling period. Also, from the Doppler spectral tracing, the peak $\mathbf{E}$ velocity, the peak $A$ velocity, and the ratio of the peak $\mathrm{E}$ and peak $\mathrm{A}$ velocities were determined.

Because of the changes in the mitral valve cross-sectional area that occur throughout diastole, determination of the absolute volumetric flow in the different portions of diastole would be extremely difficult. Therefore, the Doppler patterns of LV filling were examined by integrating several areas under the Doppler spectral tracing (Fig. 3). The measured areas included the total area under the curve in diastole or the velocity time integral, the area under the curve for the first $50 \%$ of diastole, and the area under the curve for the first $33 \%$ of diastole ( 0.33 area). The $\mathrm{E}$ area and the $\mathrm{A}$ area were measured as the triangular portion under the Doppler curve formed by extrapolating a straight line down from the peak $\mathrm{E}$ and peak A velocities to the baseline. To determine the percent of the total velocity time integral occupied by the individual areas and to normalize the data for differences in preload and diastolic cycle lengths among the patients, each individual area was divided by the total area to obtain the area fractions:

$$
\text { Area fraction }=\frac{\text { individual Doppler area }}{\text { total Doppler area }}
$$

All Doppler areas were measured using a hand-controlled crosswire cursor and a microprocessor system (Microsonics CAD 888) with a spatial resolution of $0.1 \mathrm{~mm}$. The recordings were traced along the densest portion of the Doppler curve and were extrapolated through the area of the wall filter setting to the baseline.

Data analysis: All M-mode and Doppler measurements reported are the average of 3 or more cardiac cycles. Statistical comparisons between the normal group and the hypertension group were made using an unpaired $t$ test. A 2 -tailed $\mathrm{p}$ value $<0.05$ was used to indicate a significant difference between groups. All values are reported as mean \pm standard deviation. The relation between 2 variables was assessed by linear regression analysis; $p<0.05$ was considered a significant correlation.

The beat-to-beat variation coefficients for selected diastolic measurements were calculated from 3 successive cardiac cycles of 6 studies ( 3 normal subjects and 3 patients with hypertension). The variation coefficients were: isovolumic relaxation time, $8.8 \% ;(\mathrm{dD} / \mathrm{dt}) / \mathrm{D}, 6.5 \%$; the total area under the Doppler curve, $2.4 \%$; the Doppler 0.33 area, $4.9 \%$; the $\mathrm{A}$ area, $3.8 \%$, the
TABLE \Blood Pressure and Left Ventricular Measurements in Normal Subjects and Patients with Hypertension

\begin{tabular}{lccc}
\hline \multicolumn{1}{c}{ Measurement } & $\begin{array}{c}\text { Normal } \\
\text { Subjects }\end{array}$ & $\begin{array}{c}\text { Patients with } \\
\text { Hypertension }\end{array}$ & p Value \\
\hline Systolic BP (mm Hg) & $111 \pm 8$ & $131 \pm 13$ & $0.004^{*}$ \\
Diastolic BP (mm Hg) & $62 \pm 8$ & $82 \pm 14$ & $0.006^{*}$ \\
LVDD (cm) & $5.11 \pm 0.45$ & $4.36 \pm 1.02$ & 0.09 \\
LVSD (cm) & $3.04 \pm 0.43$ & $2.52 \pm 0.65$ & 0.08 \\
SF & $0.41 \pm 0.06$ & $0.42 \pm 0.05$ & 0.55 \\
LVPW (cm) & $0.81 \pm 0.16$ & $0.79 \pm 0.19$ & 0.77 \\
Septum (cm) & $0.77 \pm 0.13$ & $0.76 \pm 0.20$ & 0.89 \\
\hline
\end{tabular}

* Statistically different between groups at the $5 \%$ level.

values are mean \pm staridard deviation.

$\mathrm{BP}=$ blood pressure; $\mathrm{LVDD}=$ left ventricular end-diastolic dimension; $L V P W=$ left ventricular posterior wall thickness; $L V S D=$ left ventricular end-systolic dimension; SF = shortening fraction.

peak A velocity, $4.2 \%$. To determine the interobserver variability, 6 records ( 3 normal subjects and 3 patients with hypertension) were analyzed independently by 2 observers. The mean percent error between the 2 observers [(first observer - second observer)/average of both observers] $\times 100$, was as follows for selected diastolic measurements: isovolumic relaxation time, $9.8 \% ;(\mathrm{dD} / \mathrm{dt}) / \mathrm{D}, 4.9 \%$; the total area under the Doppler curve, 2.8\%; the Doppler 0.33 area, 2.4\%; the A area, 3.8\%; and the peak A velocity, $2.1 \%$.

\section{Results}

A significant difference was found in the systolic and diastolic blood pressures between the 2 groups
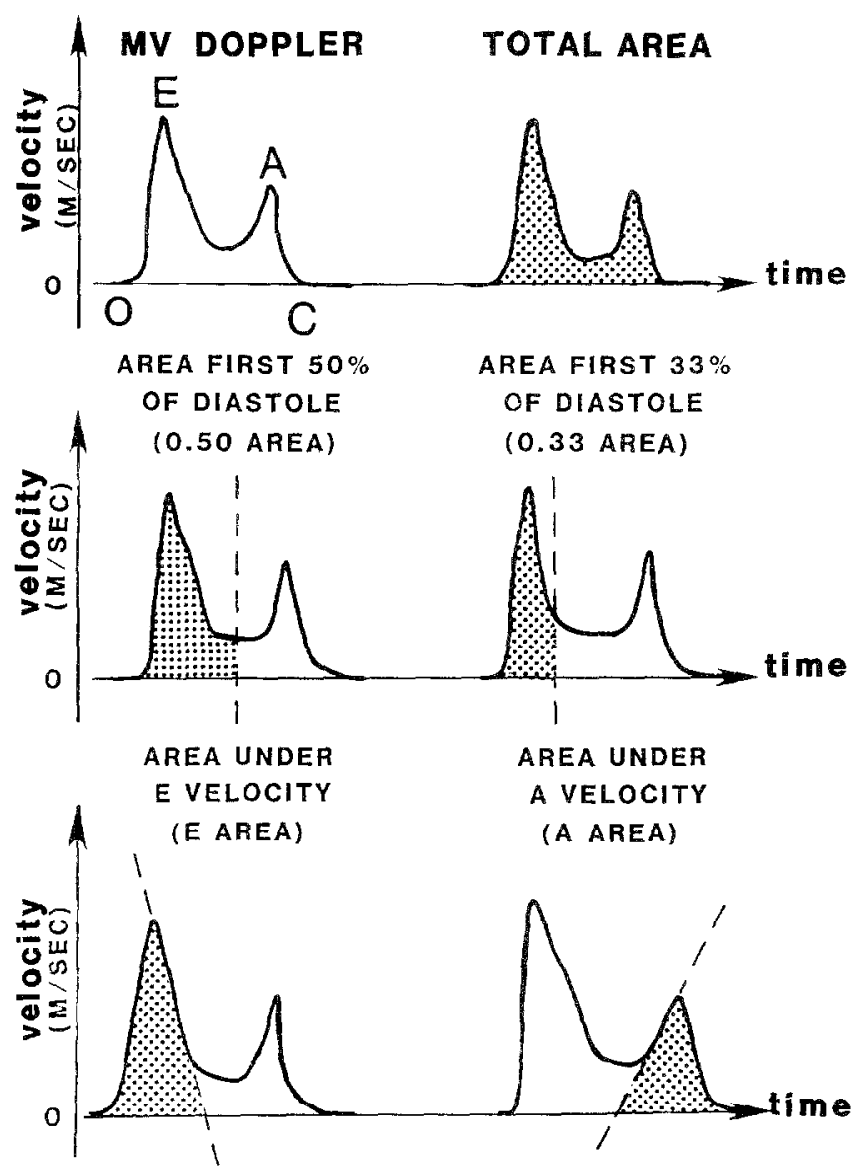

FIGURE 3. Areas measured from the mitral valve (MV) Doppler recordings. Abbreviations as in Figure 2. 
TABLE II M-Mode Echocardiographic Measurements

\begin{tabular}{lrrr}
\hline \multicolumn{1}{c}{ Measurement } & \multicolumn{1}{c}{$\begin{array}{c}\text { Normal } \\
\text { Subjects }\end{array}$} & $\begin{array}{c}\text { Patients with } \\
\text { Hypertension }\end{array}$ & p Value \\
\hline RR interval (s) & $0.88 \pm 0.12$ & $0.78 \pm 0.20$ & 0.28 \\
Isovolumic relax. time (s) & $0.03 \pm 0.01$ & $0.04 \pm 0.01$ & 0.08 \\
Total relax. time (s) & $0.16 \pm 0.04$ & $0.14 \pm 0.05$ & 0.57 \\
Relax. time (s) & $0.10 \pm 0.04$ & $0.08 \pm 0.04$ & 0.22 \\
Rapid filling period (s) & $0.10 \pm 0.06$ & $0.12 \pm 0.07$ & 0.67 \\
Peak dD/dt (cm/s) & $10.44 \pm 2.50$ & $10.88 \pm 4.30$ & 0.80 \\
(dD/dt)/D (s s $^{-1}$ ) & $2.09 \pm 0.34$ & $2.66 \pm 0.94$ & 0.14 \\
\hline
\end{tabular}

Values are mean \pm standard deviation.

$\mathrm{dD} / \mathrm{dt}=$ peak rate of increase in left ventricular dimension in diastole; $(\mathrm{dD} / \mathrm{dt}) / \mathrm{D}=$ peak rate of increase in left ventricular dimension normalized for end-diastolic dimension; relax. $=$ relaxation; $R R=$ cardiac cycle length.

TABLE III Mitral Valve Doppler Measurements

\begin{tabular}{lccc}
\hline \multicolumn{1}{c}{ Measurement } & $\begin{array}{c}\text { Normal } \\
\text { Subjects }\end{array}$ & $\begin{array}{c}\text { Patients with } \\
\text { Hypertension }\end{array}$ & p Value \\
\hline RR interval (s) & $0.94 \pm 0.21$ & $0.77 \pm 0.14$ & 0.06 \\
0 to C (s) & $0.52 \pm 0.20$ & $0.36 \pm 0.11$ & 0.06 \\
0 to $E$ (s) & $0.10 \pm 0.01$ & $0.08 \pm 0.02$ & 0.09 \\
0 to A (s) & $0.47 \pm 0.21$ & $0.31 \pm 0.10$ & 0.06 \\
0 to $E / 2$ (s) & $0.16 \pm 0.01$ & $0.16 \pm 0.08$ & 0.85 \\
Pressure half-time (s) & $0.04 \pm 0.01$ & $0.03 \pm 0.01$ & 0.62 \\
0 to $E / 1.4$ (s) & $0.13 \pm 0.02$ & $0.11 \pm 0.02$ & 0.15 \\
Peak $E$ (m/s) & $0.91 \pm 0.11$ & $1.00 \pm 0.16$ & 0.20 \\
Peak A (m/s) & $0.49 \pm 0.08$ & $0.68 \pm 0.11$ & $0.002^{*}$ \\
Ratio peak E/peak A & $1.87 \pm 0.39$ & $1.52 \pm 0.43$ & 0.095 \\
\hline
\end{tabular}

* Statistically different between groups at the $5 \%$ level.

Values are expressed as mean \pm standard deviation.

$A=$ velocity at atrial contraction; $C=$ time point of mitral valve closure; $E=$ velocity during rapid ventricular filling; $0=$ time point of mitral valve opening; $R R=$ cardiac cycle length.

(Table I); however, no differences were found in the LV dimensions, shortening fraction or LV thickness between the 2 groups. The M-mode time intervals, peak $\mathrm{dD} / \mathrm{dt}$, and $(\mathrm{dD} / \mathrm{dt}) / \mathrm{D}$ were not different between groups (Table II). The isovolumic relaxation time was the only M-mode measurement that approached being significantly different between groups (Table II). Similarly, the Doppler diastolic time intervals were not significantly different between groups (Table III). Attempts at normalizing the M-mode and Doppler diastolic time intervals by dividing the time

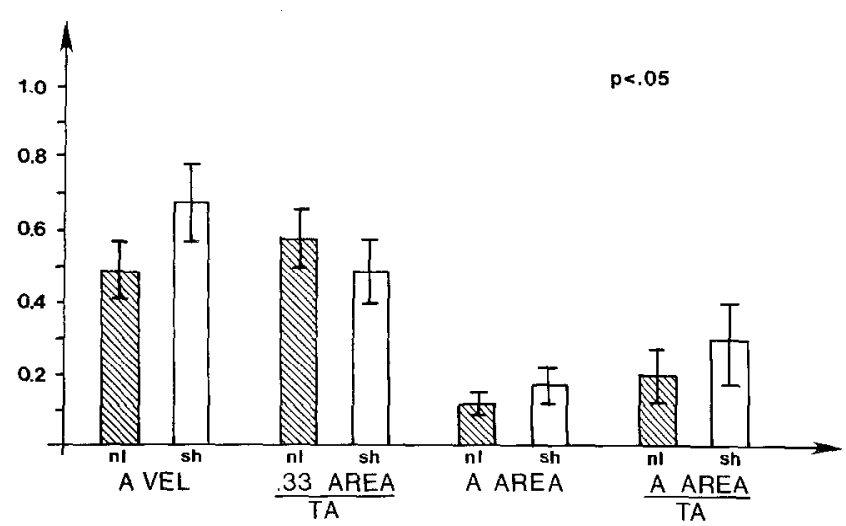

FIGURE 4. The Doppler measurements that differentiated the normal group ( $\mathrm{nl}$ ) from the hypertension group (sh). TA = total area under the Doppler curve; VEL = velocity; other abbreviations as in Figure 3 .
TABLE IV Mitral Valve Doppler Areas

\begin{tabular}{lccc}
\hline \multicolumn{1}{c}{ Measurement } & $\begin{array}{c}\text { Normal } \\
\text { Subjects }\end{array}$ & $\begin{array}{c}\text { Patients with } \\
\text { Hypertension }\end{array}$ & $\mathrm{p}$ Value \\
\hline Total area & $0.60 \pm 0.15$ & $0.58 \pm 0.11$ & 0.68 \\
0.50 area & $0.42 \pm 0.14$ & $0.38 \pm 0.10$ & 0.51 \\
0.50 area/total area & $0.69 \pm 0.05$ & $0.66 \pm 0.07$ & 0.28 \\
0.33 area & $0.36 \pm 0.13$ & $0.28 \pm 0.08$ & 0.14 \\
0.33 area/total area & $0.58 \pm 0.08$ & $0.49 \pm 0.09$ & $0.04^{*}$ \\
Earea & $0.39 \pm 0.10$ & $0.40 \pm 0.11$ & 0.80 \\
E area/total area & $0.65 \pm 0.04$ & $0.69 \pm 0.09$ & 0.26 \\
A area & $0.12 \pm 0.03$ & $0.17 \pm 0.05$ & $0.02^{*}$ \\
A area/total area & $0.20 \pm 0.07$ & $0.30 \pm 0.11$ & $0.05^{*}$ \\
\hline
\end{tabular}

* Statistically different between groups at the $5 \%$ level. Values are expressed as mean \pm standard deviation. Abbreviations as in Table III.

interval by the cycle length did not change these results. ${ }^{10}$ The peak A velocity of the systemic hypertension group was significantly higher than that of the normal subjects $(\mathrm{p}=0.002)$.

With regard to the mitral valve area measurements (Table IV), the percent of the total area in the first third of diastole was significantly lower in the systemic hypertension group $(p=0.04)$. The $A$ area and the percent of the total area under the A wave were significantly higher in the patients with hypertension $(\mathrm{p}=0.02$ and 0.05 , respectively). With regard to $\mathrm{M}$-mode and Doppler measurements, the only measurements that separated patients with systemic hypertension from normal subjects were the Doppler A-wave velocity, the Doppler $A$ area, and the percent of the Doppler total area in the first one-third of diastole and under the A wave (Fig. 4). To determine if any of these 4 variables correlated with the severity of the hypertension, linear regression analysis was performed on the data pooled from both patient groups. There was no significant correlation between these 4 variables and systolic blood pressure, diastolic blood pressure, LV posterior wall thickness or septal thickness. Also, in the patients with hypertension, there was no correlation between the blood pressure and LV thickness.

\section{Discussion}

In adult patients with chronic hypertension, M-mode echocardiographic studies have shown diminished early peak LV diastolic filling rates, prolonged isovolumic relaxation time and shortened rapid filling period. ${ }^{2,11,12,14}$ Similarly, radionuclide studies in adult patients with hypertension have revealed decreased early peak diastolic filling rates and decreased percent LV filling in the first one-third of diastole. ${ }^{10,11}$ This study shows that abnormal patterns of LV diastolic filling occur in children with mild systemic hypertension and that these diastolic filling abnormalities are detectable by mitral valve Doppler examination when standard $M$-mode indexes of diastolic function are still normal and before the development of systolic function abnormalities or LV hypertrophy on the M-mode echocardiogram.

The decrease in the percent of the total area in the first one-third of diastole and the increase in the percent of the total area under the A wave in the children with hypertension suggest a relative shift of LV filling to late 
diastole. ${ }^{2,10}$ The impaired LV filling in early diastole was accompanied by a compensatory increase in LV filling in late diastole (during atrial contraction) so that the LV end-diastolic dimension and total area under the Doppler curve of the hypertension group were normal.

M-mode versus Doppler findings: In this study, abnormalities of diastolic filling were more easily recognized by mitral valve Doppler examination than by M-mode echocardiographic techniques. Several explanations are possible for this difference. First, even though the M-mode echocardiograms were obtained while imaging the $L V$ minor axis, slight variations in the level of the cross-sectional plane from which the echocardiogram is obtained greatly influence measurements of the diastolic relaxation times and filling rates. ${ }^{17,22}$ Second, the M-mode measurements vary considerably from beat to beat and with different observers. Despite this variability, the echocardiographic relaxation times and filling rates of our normal patients were similar to values reported by others. ${ }^{3,17}$ Third, Bahler et al ${ }^{17}$ showed that the time course of diastolic relaxation is dependent on cardiac cycle length; however, the velocity of relaxation is independent of cycle length. This factor may explain why diastolic filling abnormalities were more easily detectable with the Doppler indexes (which are velocity measurements) than with echocardiographic relaxation time indexes. Bahler reported that the isovolumic relaxation time is the time interval that is most independent of cycle length. ${ }^{17}$ In our study, the isovolumic relaxation time was the only echocardiographic measurement that came close to being significantly different between the 2 groups. This finding further suggests that the remaining echocardiographic time indexes were influenced by heart rate and, therefore, were not useful in differentiating normal subjects from patients with hypertension.

There was far less beat-to-beat and interobserver variability in the mitral valve Doppler measurements. We have found that good-quality Doppler recordings suitable for analysis are easier to obtain than goodquality M-mode recordings suitable for digitizing. This is particularly true in adult patients in whom conditions such as obesity and chronic lung disease may make parasternal echocardiographic examination extremely difficult.

Factors affecting diastolic relaxation indexes: Diastolic indexes of $\mathrm{LV}$ relaxation can be influenced by several factors including heart rate and $L V$ loading conditions. ${ }^{23-25}$ Bahler et al ${ }^{17}$ showed that the rapid filling phase occupies an increasing proportion of diastole as heart rate increases. Studies in the intact heart have shown that the duration of relaxation and the velocity of lengthening are intimately related to the velocity of shortening and the inotropic state. ${ }^{26-30} \mathrm{In}$ this study, differences in the diastolic filling patterns between the normal and the hypertension group cannot be explained on the basis of differences in heart rate, systolic function or LV loading conditions. The heart rates of the 2 groups were not different, either at the time of the M-mode examination or at the time of the Doppler examination. The systolic function of the 2 groups, as assessed. by the M-mode shortening fraction, was normal. The I.V end-diastolic dimensions of both patient groups were statistically similar, indicating no intergroup differences in ventricular loading conditions. Also, division of the individual Doppler areas by the total area under the Doppler curve and division of $\mathrm{dD} / \mathrm{dt}$ by the $\mathrm{LV}$ end-diastolic dimension normalized these measurements for differences in preload.

Possible mechanisms and clinical implications of diastolic filling abnormalities: The abnormal diastolic filling noted in patients with systemic hypertension could be a result of (1) increased LV chamber stiffness caused by LV hypertrophy with normal myocardial stiffness or (2) decreased LV compliance caused by myocardial dysfunction or fibrosis. ${ }^{10,25,31}$ The patients with hypertension in our study showed diastolic filling abnormalities in the presence of normal septal and posterior wall thicknesses. Possible explanations for this finding are that (1) diastolic abnormalities occur early in the course of systemic hypertension, even preceding development of LV hypertrophy, (2) total LV mass may be increased in patients with hypertension even when $\mathrm{M}$-mode measurements show normal wall thickness, ${ }^{13}$ or (3) hypertrophy may have already regressed in the patients receiving therapy.

Six patients with hypertension who were receiving antihypertensive therapy at the time of the echo-Doppler study and whose hypertension was under good control still had Doppler diastolic filling abnormalities. Using radionuclide techniques, Inouye et $\mathrm{al}^{13}$ showed failure of reversal of $\mathrm{LV}$ diastolic filling abnormalities in patients with hypertension after therapy with diuretic, $\beta$-blocking and calcium channel-blocking drugs. These studies suggest that there may be irreversible changes in diastolic filling patterns that occur early in patients with systemic hypertension. ${ }^{13,32,33}$

Comparison of Doppler, echocardiographic and radionuclide indexes of left ventricular filling: Our values for the Doppler area fractions are very similar to Hanrath's values for percent dimensional increase measured from the echocardiogram and Inouye's values for first-third filling fraction measured from radionuclide techniques. ${ }^{2,10}$ Hanrath et $\mathrm{al}^{2}$ noted in normal subjects that $62 \pm 10 \%$ of the total change in diastolic dimension occurred during the rapid filling phase of diastole and $16 \pm 10 \%$ of the total dimensional change occurred during atrial contraction (compared with Doppler area fractions in our normal group of $0.58 \pm$ 0.08 for $0.33 \mathrm{area} /$ total area and $0.20 \pm 0.07$ for $\mathrm{A}$ area/ total area). In Hanrath's patients with hypertension, 51 $\pm 12 \%$ of the total dimensional increase occurred during rapid filling and $23 \pm 10 \%$ of the total dimensional increase occurred during atrial contraction (compared with Doppler area fractions in our hypertension group of $0.49 \pm 0.09$ for 0.33 area/total area and $0.30 \pm 0.11$ for $\mathrm{A}$ area/total area). Likewise, Inouye et $\mathrm{al}^{10}$ showed a first-third filling fraction (counts in the first one-third of diastole divided by the total stroke count) of $0.60 \pm$ 0.07 for normal subjects and $0.41 \pm 0.13$ for hypertensive patients age-matched to control subjects (comparcd with 0.33 area/total area of $0.58 \pm 0.08$ for normal subjects and $0.49 \pm 0.09$ for hypertensive patients). 
These studies, using 3 different imaging and measurement techniques, all demonstrate a shift in the $\mathrm{LV}$ filling pattern to the latter part of diastole in patients with hypertension.

In conclusion, abnormalities of diastolic filling occur early in children with systemic hypertension, before M-mode evidence of LV hyertrophy and before clinical or echocardiographic evidence of systolic dysfunction. Measurement of diastolic filling patterns from the mitral valve Doppler examination appears to be a useful method of detecting early abnormalities of diastolic function. For assessing diastolic function, the Doppler area measurements appear to have less variability than the echocardiographic diastolic time intervals and filling rates and may allow earlier detection of diastolic filling abnormalities. The Doppler technique should be useful in assessing diastolic function in a wide variety of clinical situations, including the patients with coronary artery disease, myocarditis or cardiomyopathy, LV outflow tract obstruction and previous cardiac transplantation.

Acknowledgment: We thank Margaret Young for her assistance in the preparation of this manuscript.

\section{References}

1. St. John Sutton MG, Tajik AJ, Gibson DG, Brown DJ, Seward JB, Giullani ER. Echocardiographic assessment of left ventricular filling and septal and posterior wall dynamics in idiopathic hypertrophic subaortic stenosis. Circulation 1978;57:512-520.

2. Hanrath $\mathbf{P}$, Mathey $D$, Siegert $R$, Bleifeld $W$. Left ventricular relaxation and filling pattern in different forms of left ventricular hypertrophy: an echocardiographic study. Am J Cardiol 1980;45:15-23.

3. Hanrath $P$, Mathey DG, Kremer P, Sonntag F, Bleifeld $W$. Effect of verapamil on left ventricular relaxation time and regional left ventricular filling in hypertrophic cardiomyopathy. Am J Cardiol 1980;45:1258-1264.

4. Fouad FM, Tarazi RC, Gallagher JH, Macintyre WJ, Cook SA. Abnormal left ventricular relaxation in hypertensive patients. Clin Sci 1980;59: $411 \mathrm{~s}-414 \mathrm{~s}$.

5. Bonow RO, Bacharach SL, Green MV, Kent KM, Rosing DR, Lipson LC, Leon MB, Epstein SE. Impaired left ventricular diastolic filling in patients with coronary artery disease: assessment with radionuclide angiography. Circulation 1981;64:315-323

6. Drestinski GR, Frohlich ED, Dunn FG, Messerli FH, Suarez DH, Reisin E. Echocardiographic diastolic ventricular abnormality in hypertensive heart disease: atrial emptying index. Am J Cardiol 1981;47:1087-1090

7. Polak JF, Kemper AJ, Bianco JA, Parisi AF, Tow DE. Resting early peak diastolic filling rate: a sensitive index of myocardial dysfunction in patients with coronary artery disease. J Nucl Med 1982;23:471-478.

8. Magorien DJ, Shaffer P, Bush CA, Magorien RD, Kolibash AJ, Leler CV, Bashore TM. Assessment of left ventricular pressure-volume relations using gated radionuclide angiography, echocardiography, and micromanometer pressure recordings. Circulation 1983;67:844-853.

9. Miller TR, Goldman KJ, Sampathkumaran KS, Biello DR, Ludbrook PA, Sobel BE. Analysis of cardiac diastolic function: application in coronary artery disease. J Nucl Med 1983;24:2-7.
10. Inouye I, Massie B, Loge D, Topic N, Silverstein D, Simpson P, Tubau J. Abnormal left ventricular filling: an early finding in mild to moderate systemic hypertension. Am J Cardiol 1984;53:120-126.

11. Bryhn M. Abnormal left ventricular filling in patients with sustained myo cardial relaxation: assessment of diastolic parameters using radionuclide angiography and echocardiography. Clin Cardiol 1984;7:639-646.

12. Hartford $M$, Wikstrand $J$, Wallentin $I$, Ljungman $S$, Wilhemsen $L$, Berglund G. Diastolic function of the heart in untreated primary hypertension. Hypertension 1984;6:329-338.

13. Inouye IK, Massie BM, Loge D, Simpson P, Tubau JF. Failure of antihypertensive therapy with diuretic, beta-blocking and calcium channel-blocking drugs to consistently reverse left ventricular diastolic filling abnormalities. Am J Cardiol 1984;53:1583-1587.

14. Dunn FG, Chandraratna P, de Carvalho JGR, Basta $L$, Frohlich ED. Pathophysiologic assessment of hypertensive heart disease with echocardiography. Am J Cardiol 1977;39:789-795.

15. Gibson DG, Brown D. Measurements of instantaneous left ventricular dimension and filling rate in man, using echocardiography. $\mathrm{Br}$ Heart $\mathrm{J}$ 1973;35:114t-1149.

16. Trail TA, Gibson DG, Brown DJ. Study of left ventricular wall thickness and dimension changes using echocardiography. Br Heart J 1978;40:162 169.

17. Bahler RC, Vrobel TR, Martin P. The relation of heart rate and shortening fraction to echocardiographic indexes of left ventricular relaxation in normal subjects. JACC 1983;2:926-933.

18. Sahn DJ, DeMaria A, Kisslo J, Weyman A. Recommendations regarding quantitation in M-mode echocardiography: results of a survey of echocardiographic measurements. Circulation 1978;58:1072-1083.

19. Lewis JF, Kuo LC, Nelson JG, Limacher MC, Quinones MA. Pulsed Doppler echocardiographic determination of stroke volume and cardiac output: clinical validation of two new methods using the apical window. Circulation 1984;70:425-431.

20. Rokey R, Kuo LC, Zoghbi WA, Limacher MC, Quinones MA. Determination of parameters of left ventricular diastolic filling with pulsed Doppler echocardiography: comparison with cineangiography. Girculation 1985;71: $543-550$.

21. Hatle $L$, Angelsen B. Doppler Ultrasound in Cardiology. Physical Principles and Clinical Applications. Philadelphia: Lea \& Febiger, 1985;115-122.

22. Popp RL, Filly K, Brown OR, Harrison DC. Effect of transducer placement on echocardiographic measurement of left ventricular dimensions. Am J Cardiol 1975; 35:537-540

23. Cohn PE, Liedtke AJ, Senir J, Sonnenblick HE, Urschel CW. Maximal rate of pressure fall (peak negative $\mathrm{dp} / \mathrm{dt}$ ) during ventricular relaxation. Cardiovasc Res 1972;6:263-267.

24. Benchimol A, Ellis JG. A study of the period of isovolumic relaxation in normal subjects and in patients with heart disease. Am J Cardiol 1967 19:196-206.

25. Grossman W, McLaurin LP. Diastolic properties of the left ventricle. Ann Intern Med 1976;84:316-326.

26. Brutsaert DL, Housmans PR, Goethals MA. Dual control of relaxation. Its role in the ventricular function in the mammalian heart. Circ Res 1980 47:637-652

27. Tamiya $K$, Sugawara $M$, Sakurai $Y$. Maximum lengthening velocity during isotonic relaxation at preload in canine papillary muscle. Am J Physiol 1979;237:H83-H89.

28. Weiss JL, Frederiksen JW, Weisfeldt ML. Hemodynamic determinants of time-course of fall in canine left ventricular pressure. J Clin Invest 1976 58:751-760.

29. Gaasch WH, Blaustein AS, Andrias CW, Donahue RP, Avitall B. Myocardial relaxation. II. Hemodynamic determinants of rate of left ventricular isovolumic pressure decline. Am J Physiol 1980;239:H1-H6.

30. Glantz SA, Parmley WW. Factors which affect the diastolic pressure-volume curve. Circ Res 1978;42:171-180.

31. Gaasch WH, Levine HJ, Quinones MA, Alexander JK. Left ventricular compliance: mechanisms and clinical implications. Am $J$ Cardiol 1976; 38:645-653.

32. Sen S, Tarazi RC, Bumpus FM. Biochemical changes associated with development and reversal of cardiac hypertrophy in spontaneously hypertensive rats. Cardiovasc Res 1976;10:254-261.

33. Sen S, Bumpus FM. Collagen synthesis in development and reversal of cardiac hypertrophy in spontaneously hypertensive rats. Am J Cardio 1979;44:954-958. 